\title{
Monitoria de Inglês no Ensino Superior Tecnológico: uma análise crítico-colaborativa
}

\section{Gleice De Divitiis}

Pontifícia Universidade Católica de São Paulo (PUC-SP)

\begin{abstract}
Resumo
A monitoria pode ser uma oportunidade para que o aluno aperfeiçoe e compartilhe os seus conhecimentos acerca de uma determinada disciplina com seus colegas. No entanto, muitas vezes, essa prática não gera reflexão e uma transformação interna de todos os envolvidos. Nesse sentido, o presente artigo apresenta alguns resultados obtidos no programa de monitoria de Língua Inglesa, de uma faculdade localizada em um município do interior de São Paulo. A pesquisa crítica de colaboração foi aplicada, como metodologia, com o intuito de refletir criticamente acerca das atividades desenvolvidas. Nessa instituição, em particular, a monitoria de Inglês assume um papel de destaque, visto que $90 \%$ dos estudantes afirmam não possuir conhecimentos prévios no idioma. A investigação está fundamentada nos pensamentos de Vygotsky (1989), Magalhães (1998, 2011, 2014), Freire (2008), Ninin (2011), Magalhães \& Fidalgo (2010,2011), Oliveira \& Magalhães (2011), Aguiar et al. (2014), Topping (2015), entre outros. Preliminarmente, contatou-se, após algumas discussões, um maior engajamento dos monitores no programa.

Palavras-chave: Monitoria; Língua Inglesa; Pesquisa crítica de colaboração.
\end{abstract}

\begin{abstract}
A peer tutoring program can be an opportunity for the student to improve and share his/her knowledge related to a specific subject with his/her colleagues. However, this practice seldom generates either reflection or an internal change. From this point of view, this paper presents some results seen in the English Peer Tutoring Program which takes place in a public college located in the interior of São Paulo. Critical research of collaboration was applied as a methodology, with the aim of reflecting critically about the activities used in the program. In this college, in particular, the peer tutoring program assumes an important role due to the fact that $90 \%$ of the students state they do not have any previous knowledge of the foreign language. This study is based on the ideas of Vygotsky (1989), Magalhães (1998, 2011, 2014), Freire (2008), Ninin (2011), Magalhães \& Fidalgo (2010,2011), Oliveira \& Magalhães (2011), Aguiar et al. (2014), Topping (2015), among others. Preliminary results verified, that after several discussions, the participants are more engaged in the program.

Keywords: Peer Tutoring Program; English; Critical Research of Collaboration.
\end{abstract}




\section{INTRODUÇÃO}

Os programas de monitoria no ensino superior podem ser observados como uma oportunidade de aprendizagem e aperfeiçoamento, o que permite ao graduando desenvolver atividades diversas ligadas ao campo de conhecimento do curso em que está matriculado (NASCIMENTO et al., 2010, p. 5).

Além disso, por meio da monitoria há a integração e a interação entre estudantes de diversos cursos. E, quando estabelecido de maneira eficaz, o programa pode contribuir na efetividade do processo de ensino-aprendizagem da disciplina alvo.

Geralmente, o aluno selecionado para a monitoria é aquele que já tenha cursado a disciplina alvo (com desempenho satisfatório) ou, possui aproveitamento de estudos obtido em outro curso superior (ou proficiência em cursos livres, no que tange, especificamente, à matéria de Inglês na faculdade investigada).

No que se refere à Língua Inglesa, na faculdade de tecnologia em que a pesquisa foi realizada, percebe-se que, ao investigar o histórico dos alunos ingressantes, por meio de questionários realizados nos primeiros dias de aula a cada semestre, cerca de $90 \%$ menciona não possuir conhecimentos relacionados ao idioma. Além disso, 83,6\% dos candidatos que participam do vestibular promovido pela instituição de ensino superior são oriundos de escolas públicas.

Dessa forma, a monitoria de Língua Inglesa desempenha um papel preponderante, inclusive, no que tange à evasão, visto que em quatro dos cinco cursos tecnológicos oferecidos pela faculdade, a disciplina faz parte da grade e, usualmente, alunos relatam dificuldades na aprendizagem dessa língua estrangeira.

Nesse contexto, em 2015, é implantado o programa de monitoria referente à disciplina de Inglês, por iniciativa de uma docente que não era concursada e, cujo contrato, por tempo determinado, extinguiu-se em dezembro do mesmo ano. A partir de março de 2016, o programa é retomado pela autora deste artigo.

Para atuar como monitor, os alunos do primeiro semestre de todos os cursos tecnológicos que possuem Inglês em suas grades curriculares realizam um teste de proficiência, na primeira semana de aula, elaborado por um núcleo de idiomas administrado pela autarquia responsável pelas faculdades e aplicado na própria unidade. Se aprovado, com média superior a $60 \%$ em cada etapa da prova (ao todo são seis etapas, equivalentes aos seis semestres em que a disciplina é ministrada de maneira 
intracurricular), o aluno é dispensado de cursar a matéria e convidado a ingressar no programa.

Outro meio de dispensa e ingresso na monitoria é pelo aproveitamento de estudos, isto é, se o graduando já cursou a disciplina de Inglês em outra instituição de ensino superior ou possui certificado de proficiência no idioma. Os documentos são encaminhados à secretaria acadêmica que analisa a possibilidade de dispensa. Após esse processo e, se aprovado, o estudante é convidado a participar do programa em questão.

Para a realização da monitoria, é preciso que todos os envolvidos estejam integrados e em constante aperfeiçoamento. Assim, a faculdade oferece para os monitores de Língua Inglesa o curso de "Formação de Monitores de Inglês", com aulas ministradas pela autora deste artigo. A atividade ocorre, semanalmente, com carga horária de $1 \mathrm{~h}$. Não há uma duração determinada para o seu término, pois são inseridos novos assuntos em fluxo contínuo. É um momento criado, também, para o compartilhamento de experiências e a proposição de novas técnicas de ensino que possam aproximar a disciplina de Inglês do cotidiano dos discentes. Alguns estudantes relatam que já perderam oportunidades de emprego e/ou aumento de salário por conta de não falar e/ou escrever em Inglês. Assim, a disponibilização de atividades voltadas ao contexto histórico e social dos graduandos pode contribuir na reversão de tais quadros.

Dentro desse panorama, além de preparar os monitores para os principais exames internacionais (com aulas de gramática em nível avançado e atividades relativas às habilidades de listening, speaking, reading e writing), o curso discute temáticas relacionadas ao campo da Didática e Metodologia de Ensino. A cada aula, um tema é apresentado. Se o assunto é extenso, encontros virtuais são agendados eventualmente.

Ademais, era necessário propiciar aos envolvidos momentos de reflexão acerca da prática realizada e, analisar se o projeto resultaria em uma transformação interna no que tange à percepção do processo de ensino-aprendizagem de Língua Inglesa. Dessa forma, optou-se como metodologia de investigação, a pesquisa crítica de colaboração. $O$ trabalho ainda está em andamento, no entanto, após três encontros crítico-reflexivos realizados em poucos meses de estudo, já foi possível considerar alguns resultados preliminares.

Segundo Magalhães (2011, p. 15), a pesquisa crítica de colaboração

possibilita aos pesquisadores a construção de contextos de negociação (colaborativos), em projetos de formação contínua, com foco na compreensão e na transformação de sentidos e significados que dão forma às escolhas diárias (MAGALHÃES, 2011, p.15). 
Embora existam divergências no que refere ao significado do termo colaboração, entende-se, de forma geral, colaboração como o encontro de pessoas que trabalham em prol de um objetivo comum, sem uma organização hierárquica (TORRES; ALCANTARA; IRALA, 2004, p. 3). E, é exatamente dentro desse pensamento que a análise foi delineada: participantes com os mesmos ideais, sem quaisquer preocupações com hierarquia, em busca de aprendizado, de uma transformação interna que possa contribuir efetivamente com as suas práticas futuras.

\section{A MONITORIA DE INGLÊS:}

O projeto de monitoria de Língua Inglesa observado neste trabalho ocorre em uma faculdade pública de tecnologia, localizada em um munícipio do interior de São Paulo, a cerca de 130 km da Capital. Em 2016, a localidade possuía uma população estimada em 117.823 habitantes ${ }^{1}$.

Nessa IES, com onze anos de existência e cerca de dois mil alunos matriculados regularmente, são oferecidos cinco cursos de graduação tecnológica, com duração de três anos (seis semestres). São eles: Automação Industrial (vespertino e noturno); Gestão Empresarial (vespertino e noturno); Gestão Empresarial EAD; Manutenção Industrial (matutino e noturno); Gestão da Tecnologia da Informação (matutino e noturno) e Produção Fonográfica (vespertino). Semestralmente, são asseguradas 380 vagas para o ingresso na instituição de ensino superior por intermédio de exame vestibular. Como mencionado anteriormente, dos vestibulandos inscritos, 83,6\% são oriundos de escolas públicas.

A inserção da Língua Inglesa, em praticamente todos os $\operatorname{cursos}^{2}$, deve-se à política de inclusão e formação integral dos estudantes criada pela autarquia que administra os estabelecimentos no Estado de São Paulo. Inclusive, há o incentivo de formações continuadas para os professores, congressos, workshops e, para os alunos, o oferecimento de bolsas de intercâmbio em parceria com diversas entidades. No segundo semestre de 2017, duas alunas da unidade foram selecionadas para um curso nos Estados Unidos e para um programa de intercâmbio, de um semestre, no Chile.

\footnotetext{
${ }^{1}$ Dados coletados a partir de informações do Instituto Brasileiro de Geografia e Estatística (IBGE). Disponível em 21 set. 2016, no endereço: http://www.cidades.ibge.gov.br/

${ }^{2}$ Exceto no curso de Tecnologia em Automação Industrial.
} 
Participam do programa de monitoria, no ano de 2017, 14 monitores, oriundos dos cursos de: Gestão da Tecnologia da Informação (01 monitor), Gestão Empresarial (04 monitores), Produção Fonográfica (08 monitores) e Manutenção Industrial (01 monitor). Cada monitor realiza os atendimentos semanalmente, durante uma hora.

Qualquer aluno interessado pode buscar os atendimentos para a solução de dúvidas, apoio na realização de exercícios, revisão para avaliações, etc. Inclusive, não há um limite no número de participações na monitoria. Isto é, o estudante pode consultar os monitores sempre que considerar conveniente e/ou houver necessidade. Atualmente, o projeto recebe uma média de 20 alunos por semana, conforme dados obtidos nas listas de presença preenchidas pelos monitores.

\section{A PESQUISA CRÍTICA DE COLABORAÇÃO}

A pesquisa colaborativa e, mais tarde, a pesquisa crítica de colaboração, particularmente no campo da Linguística Aplicada, atualmente, é desenvolvida e aprimorada por meio de diversos estudos e pesquisas. Em 1990, Magalhães inicia as investigações nessa área e, já na sua tese de doutorado, institui a pesquisa colaborativa, com o objetivo de ouvir os participantes da análise (NININ, 2011, p. 99). Tal abordagem está embasada na teoria Sócio-Histórica e na Zona de Desenvolvimento Proximal (ZDP) proposta por Vygotsky e seus discípulos.

\footnotetext{
A Zona de Desenvolvimento Proximal (ZDP) é a distância entre o nível de desenvolvimento real, constituído por funções já consolidadas pelo sujeito, que lhe permitem realizar tarefas com autonomia, e o nível de desenvolvimento potencial, caracterizado pelas funções que estariam em um estágio embrionário e não amadurecidas". (VYGOTSKY, 1989, p. 97)
}

$\mathrm{Na}$ ZDP, "as situações de aprendizagem vividas pelo sujeito e mediadas por sujeitos mais experientes, geram mudanças qualitativas e impulsionam o processo de desenvolvimento do indivíduo" (SOUZA; ROSSO, 2011).

Averígua-se, também, que na pesquisa crítica de colaboração não existem materiais prontos, consolidados. Há um processo em construção que somente será firmado a partir da contribuição de todos os envolvidos. De acordo com Magalhães (2014, p. 24), o conceito de colaboração é visto por Vygotsky como essencial para o processo de formação do ser humano, a partir das relações sócio-históricas coletivas. E, nesse 
processo, a linguagem é protagonista visto que é por meio dela que brotam a crítica e a reflexão.

Magalhães (2011, p. 15), traz as considerações de Smyth (1992), acerca do pensamento de Paulo Freire para ressaltar que toda a produção do conhecimento deve levar em conta o contexto histórico-cultural dos agentes envolvidos. "É por meio da educação que tais desigualdades podem ser transformadas" (MAGALHÃES, 2011, p. $15)$.

$\mathrm{Na}$ investigação realizada por pesquisadores da Universidade Federal de Juiz de Fora (UFJF), Schapper et al. (2014) constataram a urgência de trabalhos que gerassem a reflexão crítica no que se refere aos estudos educacionais. Celani (2011, p. 7), inclusive, enfatiza que ainda existem poucos estudos (organizados em livros) relacionados à pesquisa crítica de colaboração como método para se investigar a formação docente, embora exista um número expressivo de dissertações, teses e artigos publicados no meio acadêmico, principalmente, por professores e alunos do Programa de Pós-Graduação em Linguística Aplicada e Estudos da Linguagem (LAEL) da Pontifícia Universidade Católica de São Paulo (PUC-SP).

Para existir uma colaboração realmente crítica, o participante precisa repensar as suas ações por meio de um exercício de aprofundamento e criatividade, com o objetivo de se alcançar a esperada transformação interna e da prática em sala de aula.

Oliveira \& Magalhães (2011, p.68) ao discutirem a pensamento de González Rey \& Martinez (1989, p. 15), observam que

\begin{abstract}
a ação do professor não depende somente dos conhecimentos que possui sobre sua área e sobre seu aluno, ou dos recursos e estratégias apontados pela literatura especializada, mas de como essas informações se articulam em sua configuração subjetiva, condição essencial para que o professor possa se expressar em uma ação pedagógica reflexiva (MAGALHÃES, 2011, p. 68)
\end{abstract}

Já Magalhães (2014, p. 22) quando analisa Engeström (2009, p. 321) relata que quando se pensa em pesquisar a formação e intervir nesse processo, a escolha metodológica deve ser intencional, com o intuito de gerar um ambiente realmente colaborativo:

Trata-se de um procedimento de pesquisa em que compreensão e transformação estão dialeticamente relacionadas desde seu início, em oposição a uma intervenção linear, voltada à reprodução e à transmissão de conhecimento considerado válido pelos formadores. Como coloca, nas intervenções formativas, os sujeitos participantes constroem uma solução, um conceito ou um conteúdo inovador que não foram pensados pelo pesquisador, uma vez que toda a base teórico-metodológica do projeto inicial é sujeita a 
negociações. O objetivo é constituir participantes criativos quanto ao uso inovador e não repetitivo das questões trabalhadas, em outros contextos de ação. (MAGALHÃES, 2014, p. 22)

Esse processo crítico-reflexivo, segundo Oliveira \& Magalhães (2011, p. 69), traz dúvidas, inquietações e tensões por conta da diversidade de ideias. O trabalho em equipe é sempre conflituoso. Mas, é nesse espaço diverso e, ao mesmo tempo, enriquecedor em que todos participam igualmente, é que os questionamentos podem ser analisados e aprofundados. Em outras palavras, para construir e/ou reconstruir e transformar, é preciso desconstruir. E, obviamente, a pesquisa crítica de colaboração deve refletir a sociedade com seus conflitos, inquietações e contradições:

\begin{abstract}
Assim, o processo colaborativo não implica que todos os participantes tenham a mesma "agenda" ou o mesmo poder institucional ou de saber, mas que tenham possibilidades de apresentarem e negociarem suas representações e valores na compreensão da realidade e de entenderem as interpretações dos envolvidos. Também não significa quem em todas as situações, professor e pesquisador dividam igualmente o "poder" nas decisões, mas que isso esteja claro aos participantes e seja colocado em discussão. Na verdade, este é um aspecto que necessita ser mantido sob constante vigilância pelo pesquisador, principalmente nas pesquisas em que este ocupa um lugar marcado institucionalmente. (MAGALHÃES, 1998, p. 173-174)
\end{abstract}

Ao invés de se pensar individualmente ou de forma impositiva, a pesquisa crítica de colaboração visa criar momentos de empoderamento grupal (MAGALHÃES \& FIDALGO, 2010, p. 776).

\title{
A PESQUISA REALIZADA
}

Ao se optar pela pesquisa crítica de colaboração, deve-se ter ciência de que a base desse método são os encontros ou reuniões reflexivas. Os encontros se constituem como momentos de ensino-aprendizagem, para a admissão de dúvidas, incertezas e para o questionamento (AGUIAR et al., 2014).

Machado et al. (2015) enfatizam a partir da proposta de Magalhães (2007, p. 98) que os encontros ou sessões reflexivas "têm o objetivo de propiciar contextos para que professores e pesquisadores externos problematizem, explicitem e, eventualmente, modifiquem as formas como compreendem sua prática e a si mesmos". 
Durante os encontros crítico-reflexivos ${ }^{3}$, foram e serão apresentadas as gravações dos atendimentos dos monitores que se dispuseram a realizá-las (antes de gravar o atendimento, o aluno que buscou a monitoria consentiu participar da pesquisa, por meio de termo assinado), aplicados questionários semiestruturados e/ou abertos, além da sugestão de atividades que possam aprimorar o projeto. Espera-se que todas essas ações possam suscitar e colocar o debate em uma posição estratégica, com o objetivo de solucionar dúvidas, contradições e desafiar todo o grupo para o aperfeiçoamento e a transformação reflexiva.

Nesse quadro, colocar como central a discussão de colaboração possibilita trazer à tona as contradições, nas relações entre os participantes de uma pesquisa ou de um projeto de extensão. Por isso, traz a necessidade de enfatizar a natureza da agência humana, como intencionalmente orientada ao objeto da atividade, nas relações entre os diferentes grupos de participantes. (MAGALHÃES, 2011, p. 19-20)

$\mathrm{O}$ ato de incluir a gravação dos atendimentos em vídeo, durante os encontros, é a oportunidade de o monitor analisar a sua própria prática e refletir acerca de suas ações para a busca do aperfeiçoamento. Aguiar et al. (2014) analisam que tal exercício afeta o participante emocionalmente, para a percepção de suas falhas e acertos, o que traz para a discussão a necessidade de transformação e de recriação de sua carreira profissional.

Já na aplicação dos questionários semiestruturados ou semiabertos, segundo Duarte (2008, p. 66), busca-se “[...] tratar da amplitude do tema, apresentando cada pergunta da forma mais aberta possível". Ainda, de acordo com o autor:

Uma vantagem desse modelo é permitir criar uma estrutura para comparação de respostas e articulação de resultados, auxiliando na sistematização das informações fornecidas por diferentes informantes. O roteiro de questõeschave serve, então, como base para a descrição e análise em categorias, como se verá adiante. (DUARTE, 2008, 67)

No que tange às questões abertas, Duarte $(2008$, p. 65) salienta que o questionário

tem como ponto de partida um tema ou questão ampla e flui livremente, sendo aprofundada em determinado rumo de acordo com aspectos significativos identificados pelo entrevistador enquanto o entrevistado define a resposta segundo seus próprios termos, utilizando como referência seu conhecimento, percepção, linguagem, realidade, experiência. Dessa maneira, a resposta a uma questão origina a pergunta seguinte e uma entrevista ajuda a direcionar a subsequente. A capacidade de aprofundar as questões a partir das respostas torna este tipo de entrevista muito rico em descobertas (DUARTE, 2008, p. 65).

\footnotetext{
${ }^{3}$ Termo que será utilizado pela autora ao longo deste trabalho. Optou-se por essa terminologia por se tratar de uma pesquisa crítica, em que buscar-se-á a reflexão coletiva, com o intuito de uma transformação interna das práticas de todos os sujeitos envolvidos.
} 


\section{PERFIL DOS PARTICIPANTES}

Participarão desta investigação, além da pesquisadora, 14 monitores. Atualmente, são aprovados no exame de proficiência, a cada semestre, cerca de 10 alunos. Todos são convidados a integrar o programa de monitoria e, aproximadamente, 80\% desses aceitam participar. Em 2017, apenas uma monitora é remunerada. Os demais recebem, semestralmente, 10 horas de AACCs (Atividades Acadêmico-Científico-Culturais), certificado emitido pela faculdade e o curso de formação para monitores. Três monitores de Inglês participam de programas relativos a outras disciplinas, como por exemplo, Matemática e Acústica.

Os perfis apresentados, abaixo, foram elaborados a partir das respostas obtidas por meio de questionários semiestruturados aplicados durante o primeiro encontro críticoreflexivo realizados e nas reuniões de monitores, que ocorrem mensalmente. Nesta pesquisa, os nomes dos participantes foram substituídos por letras, com o intuito de preservar as suas identidades:

- Pesquisadora: licenciada em Letras (Inglês/Português), especialista em Psicopedagogia, mestre em Comunicação Social e doutoranda em Linguística Aplicada e Estudos da Linguagem. Atua na faculdade investigada há um ano e meio;

- Monitora A: 18 anos de idade, estudante de Produção Fonográfica, nascida em São Paulo e residente no município em que a faculdade está localizada;

- Monitor B: 26 anos de idade, estudante de Gestão Empresarial, nascido e residente no município em que a faculdade está localizada;

- Monitora C: 24 anos de idade, estudante de Produção Fonográfica, residente a $100 \mathrm{~km}$ da faculdade;

- Monitor D: 28 anos de idade, estudante de Produção Fonográfica, residente em São Paulo;

- Monitor E: 22 anos de idade, estudante de Manutenção Industrial, residente a 35 $\mathrm{km}$ da faculdade;

- Monitor F: 23 anos de idade, estudante de Gestão Empresarial, residente a 60 $\mathrm{km}$ da faculdade; 
- Monitora G: 24 anos de idade, estudante de Gestão da Tecnologia da Informação, residente no município em que a faculdade está instalada;

- Monitor H: 22 anos de idade, estudante de Produção Fonográfica, residente em um município da Grande São Paulo;

- Monitor I: 23 anos de idade, estudante de Produção Fonográfica, residente a 60 $\mathrm{km}$ da faculdade;

- Monitora J: 17 anos de idade, estudante de Produção Fonográfica, residente em São Paulo;

- Monitor K: 25 anos de idade, estudante de Produção Fonográfica, cursa a segunda graduação e reside a $50 \mathrm{~km}$ da faculdade;

- Monitor L: 34 anos de idade, estudante de Produção Fonográfica, cursa a segunda graduação e reside a $25 \mathrm{~km}$ da faculdade;

- Monitor M: 29 anos de idade, estudante de Gestão Empresarial, reside no município em que a faculdade está localizada;

- Monitor N: 28 anos de idade, estudante de Gestão Empresarial, cursa a segunda graduação e reside no município em que a faculdade está localizada.

Para o monitor M, o que o motivou a participar do programa foi "para ajudar as outras pessoas com dificuldades". O participante E detalhou mais o porquê da sua escolha em se tornar monitor: "Em função da globalização, o inglês tem sido cada vez mais requerido nas diversas áreas profissionais. Percebi que muitos dos meus colegas da faculdade têm dificuldade com o idioma. Então, vi nessa situação uma oportunidade de ajudar e contribuir no aprendizado das pessoas".

\section{RESULTADOS OBTIDOS}

A partir do princípio de que a temática proposta não será esgotada somente com esta investigação, serão realizados, inicialmente, cinco encontros crítico-reflexivos ${ }^{4}$, com a duração entre $1 \mathrm{~h} 30$ e $2 \mathrm{~h}$ e, com a periodicidade quinzenal ou mensal ${ }^{5}$. Em cada reunião, espera-se atingir diferentes objetivos. São eles:

\section{Primeiro Encontro (já realizado):}

\footnotetext{
${ }^{4}$ Quatro encontros já foram realizados nos meses de junho, julho, agosto e setembro de 2017.

${ }^{5}$ Encontros definidos de acordo com a disponibilidade de todos os participantes.
} 
A proposta de pesquisa foi apresentada. Houve, também, a aplicação de um questionário semiestruturado para que a pesquisadora compreendesse o perfil de todos os participantes. Ademais, foi solicitada a gravação de alguns atendimentos. O intuito inicial foi analisar a importância da monitoria, do curso de capacitação e das percepções acerca dos atendimentos.

No que se refere aos questionários, constatou-se que 50\% dos monitores têm idade entre 22 e 25 anos; aproximadamente $30 \%$ entre 26 a 30 anos; por volta de $10 \%$ entre 18 e 21 anos e, menos de $10 \%$, acima de 31 anos. Com relação ao local de residência, verificou-se que quase $60 \%$ dos envolvidos residem em outro município, inclusive na capital.

Questionados sobre a importância do curso de capacitação, houve unanimidade no que se refere à contribuição da atividade para a performance nos atendimentos e, também, para o aperfeiçoamento no idioma Inglês. Duas monitoras (A e J) relataram que após a atuação, decidiram buscar oportunidades como instrutores em cursos de idiomas. Dessas, a Monitora A conseguiu a colocação profisssional em um instituto de idiomas localizado na cidade em que a faculdade está instalada e foi incentivada a se matricular, também, em um curso de Licenciatura em Letras: “A monitoria despertou uma vontade grande de atuar como professora. Na escola de idiomas em que atuo, trabalho com crianças e adultos. É uma experiência muito relevante para a minha vida".

Com relação à evolução no rendimento dos estudantes, a partir dos atendimentos realizados, sete monitores $(\mathrm{A}, \mathrm{B}, \mathrm{C}, \mathrm{F}, \mathrm{G}, \mathrm{K}$ e N) afirmaram que os alunos mencionaram melhorias nas notas após comparecer à monitoria. Inclusive, o Monitor B trouxe para a discussão o exemplo de dois estudantes que enfatizaram estar prestes a desistir do curso em que estavam matriculados por conta de dificuldades na disciplina de Inglês, no entanto, o acompanhamento individual oferecido fez com que mudassem de ideia, pelo menos, provisoriamente.

\section{Segundo Encontro (já realizado):}

Foi promovida uma discussão acerca dos atendimentos gravados e elaboradas atividades que pudessem ser desenvolvidas durante os atendimentos semanais. $O$ objetivo principal foi analisar a sua própria prática e verificar o comportamento dos alunos que buscam pela monitoria. 
Percebeu-se que alguns monitores não ficaram à vontade com a exposição diante da câmera, mesmo que de seu próprio celular. Dos 14 monitores que atuaram no primeiro semestre de 2017 no referido programa, 11 realizaram as gravações (A, C, D, E, F, G, $\mathrm{H}, \mathrm{I}, \mathrm{J}, \mathrm{M}$ e N).

Segundo a Monitora C,

o vídeo fez com que eu percebesse algumas coisas que eu considero erradas, mas que eu não tinha reparado e, muito menos parado para pensar sobre isso. Foi um momento muito interessante de percepção. Farei esse exercício mais vezes. Será imprescindível a partir de agora.

$\mathrm{O}$ monitor $\mathrm{N}$ salientou que a análise de sua atuação poderia ser realizada em mais oportunidades:

Tenho a certeza de que se fizéssemos este exercício mais vezes, poderíamos nos aperfeiçoar ainda mais. Durante a gravação do meu atendimento, observei que a minha postura estava um pouco equivocada. Poderia ter ficado mais próximo do aluno, ao seu lado. Utilizei mais a lousa, o que, para mim, gerou um distanciamento. Vou verificar, inclusive, se no meu trabalho, quando atendo alguém, sou distante também. Se for permitido, farei essas gravações mais vezes.

A monitora A, "mais acostumada com gravações", devido a sua atuação como cantora, elencou alguns momentos do atendimento em que ela afirmou conter falhas:

$\mathrm{O}$ ato de filmar não me incomodou. Aliás, como cantora, estou acostumada a isso. Mas, fiquei receosa de verificar as minhas falhas. E, foram algumas: falar mais que o aluno, não ter muita paciência para refazer atividades, não mostrar para o aluno que eu estava ali para ajudar, entre outras. Não é tão fácil quanto parece. No entanto, dou o meu melhor, sempre.

Já o Monitor D analisou a proximidade entre os alunos durante os atendimentos:

Pude perceber, por meio das gravações, o quanto os alunos ficam à vontade com os monitores. Não há aquelas cobranças que os professores fazem durante as aulas. Eu mesmo tenho muita vergonha de falar alguma coisa que não deveria na sala de aula. São quarenta alunos. Nem pensar. Em alguns dias, vou para a casa cheio de dúvidas, mas não pergunto para o professor na frente de todos. Seria muito bom se todas as matérias oferecessem monitoria. Ninguém seria reprovado. $\mathrm{O}$ vídeo foi muito importante, também, para eu ver como trabalho e fazer uma autoavaliação.

\section{Terceiro Encontro (já realizado):}

No terceiro encontro, os alunos foram convidados a ler dois textos: "Mediação e Zona de Desenvolvimento Proximal (ZDP): entre pensamentos e práticas docentes”, de Souza \& Rosso (2011) e "Grupos de Consenso: Uma Proposta de Aprendizagem Colaborativa para o Processo de Ensino-Aprendizagem", de Torres, Alcantara \& Irala 
(2004). Antes de entregar cópias aos monitores, a pesquisadora selecionou alguns trechos dos artigos para discussão. Priorizaram-se trechos que citavam a importância da interação entre os pares e como os programas de monitoria nas faculdades e universidades podem colaborar efetivamente para a diminuição das taxas de reprovação e evasão.

$\mathrm{O}$ Monitor $\mathrm{N}$ enfatizou que as leituras foram importantes para conhecer as teorias que mostram "o funcionamento dos programas de monitoria":

Foi muito relevante a professora trazer esses textos. Não são autores que conhecemos ou, que iremos ler todos os seus livros. Não fazem parte dos nossos cursos. Mas, pude conhecer um pouco das teorias que mostram o papel dos programas de monitoria. Na faculdade de Direito (curso a segunda graduação), as monitorias não eram tão incentivadas como aqui. Hoje, tenho a certeza de que perdemos muito com isso.

Também, foi elaborado um questionário semiestruturado que será aplicado com os alunos que buscam os atendimentos. Entre as questões, estão:

- Por que você buscou os atendimentos no Programa de Monitoria de Inglês?

- Quais são as suas maiores dificuldades no que se refere à disciplina de Inglês?

- Após participar dos atendimentos, você percebeu alguma melhora no rendimento? Detalhar.

As perguntas terão como intuito identificar, prioritariamente, a importância do programa de monitoria para a melhoria no desempenho dos alunos. E, se esse possível melhor aproveitamento foi responsável pela redução das taxas de evasão e reprovação na instituição de ensino superior investigada.

\section{Quarto Encontro (já realizado):}

Foram discutidos os resultados da leitura e dos questionários realizados com os alunos. Foi aplicado um novo questionário (desta vez, aberto) aos participantes (monitores), com o intuito de se observar se ocorreu alguma mudança de perspectiva em comparação com o primeiro encontro realizado.

$\mathrm{Na}$ grande maioria dos questionários, as respostas dos alunos que buscam pelos atendimentos foram bem curtas e inespecíficas. Como por exemplo, quando perguntados das razões pelas quais procuraram a monitoria, grande parte respondeu: 
"Porque não sei Inglês". Com relação às dificuldades, poucos, souberam explicá-las, o que segundo o monitor B prejudica a qualidade da monitoria realizada:

Ao comparar os quinze questionários, vi que são praticamente iguais. Os alunos, dificilmente, trazem claras as suas dúvidas. Então, perdemos um bom tempo para tentar perceber o que os levou lá. Penso que, às vezes, o aluno falta nas aulas de Inglês e recorre à monitoria para 'salvá-lo' de uma reprovação, o que não vejo como objetivo principal. Quase sempre, isso me entristece e me preocupa.

Nesse sentido, o monitor F concordou com as afirmações de B:

Tenho alunos que me procuram somente nos dias de prova. É triste, mas vejo como um dos objetivos da monitoria: revisar conteúdos para a avaliação. O complicado é quando o indivíduo falta em todas as aulas e quer que façamos "milagres". Eu sempre explico que é difícil resolver tudo, mostrar todo o conteúdo. Monitoria não substitui aula. Para mim, é um complemento, é a chance de resolver algumas questões que ficaram sem entendimento na aula regular. Ao, mesmo tempo, vejo bons resultados. Já observei alguns alunos que queriam desistir do curso por causa do Inglês. Hoje, com a monitoria, pensam diferente.

Embora as respostas fossem inconclusivas, quando a pergunta se referiu à melhoria no rendimento na disciplina de Inglês, 12 dos 15 alunos consultados relataram que a monitoria os ajudou no aumento de suas notas, o que para $\mathrm{J}$, é o reconhecimento de que a monitoria apresenta resultados:

Temos problemas, sim temos. Todavia, mesmo aqueles alunos que não comparecem às aulas regulares, percebem que a monitoria colabora com o aprendizado deles. Sempre enfatizo que monitoria não substitui aula e, tenho a certeza de que eles sabem disso. Conversei esses dias com uma das professoras de Inglês e ela disse que houve até aumento na presença de alguns estudantes. Tudo é uma cultura. Em breve, eles perceberão mais claramente o papel da monitoria.

Já no que se refere às leituras solicitadas no encontro anterior, os monitores $\mathrm{H}, \mathrm{I}, \mathrm{K}$ e L consideraram a linguagem acadêmica um pouco complexa, entretanto, L revelou que percebeu o seu trabalho nos textos: "Alguns termos são difíceis. Mas, consegui perceber o meu trabalho, a minha função lá”.

\section{Quinto Encontro:}

Será o fechamento da pesquisa. Haverá mais um debate, com o objetivo de se comparar o questionário respondido no primeiro encontro, com a atividade realizada no quarto. Também, será elaborado um relatório escrito por todo o grupo. O objetivo será 
verificar se a investigação trouxe, realmente, alguma transformação para a prática dos participantes.

\section{PERCEPÇÕES ACERCA DOS ENCONTROS:}

Um dos papeis fundamentais da universidade é a promoção de atividades críticas e reflexivas. Infelizmente, isso não acontece com frequência, o que torna a formação do graduando incompleta e inconsistente. A presente investigação buscou e busca, em todos os seus momentos, uma formação crítica por meio da argumentação/negociação e, de forma alguma, por algum modo de imposição (LIBERALI, 2011, p.42). Todos foram convidados e, por total livre e espontânea vontade, demonstraram a cada encontro o interesse de compreender acerca do seu papel como monitor e, como o seu trabalho poderia ser capaz de transformar a vida de outros alunos.

Durante os quatro encontros crítico-reflexivos realizados até agora, houve um despertar da curiosidade pela pesquisa e pelo aprendizado dos colegas. Como afirmou Paulo Freire (2008, p. 32), a transição da ingenuidade para a criticidade não é um processo automático:

\footnotetext{
A curiosidade como inquietação indagadora, como inclinação ao desvelamento de algo, como pergunta verbalizada ou não, como procura de esclarecimento, como sinal de atenção que sugere alerta faz parte integrante do fenômeno vital. Não haveria criatividade sem a curiosidade que nos move e que nos põe pacientemente impacientes diante do mundo que não fizemos, acrescentando a ele algo que fazemos (FREIRE, 2008, p. 32).
}

Freire (2008, p. 39) também salienta que é a reflexão crítica da prática atual que faz com que a próxima seja melhorada, aperfeiçoada. O Monitor E, no segundo encontro comentou: "Não quero ser professor, mas quero aperfeiçoar o meu trabalho aqui. Estou ansioso para conhecer, aprofundar-me no que é ser monitor. Assim espero ajudar os meus colegas e, talvez, ajudar eu mesmo".

A oportunidade de aprofundamento gerada pela presente pesquisa, inclusive, aumentou a frequência dos monitores no projeto. Conforme dados obtidos nas listas de presença deixadas na coordenação de cursos para que os monitores assinem a cada atendimento realizado, observou-se que antes das reuniões, $20 \%$ dos monitores não compareciam semanalmente (as ausências eram justificadas com atestados médicos e comprovantes de empresas). Já, após o início da pesquisa crítica de colaboração, as faltas foram reduzidas em cerca de $10 \%$, o que revelou um crescimento considerável no 
interesse pelas monitorias após a chance de investigar e aprimorar o seu próprio trabalho. Espera-se que tais resultados sejam duradouros e possam se multiplicar nas turmas de monitores vindouras.

\section{CONSIDERAÇÕES FINAIS:}

Embora o programa de monitoria realizado pela faculdade observada não tenha como intuito formar professores, visto que os cursos oferecidos são de graduação tecnológica (e não licenciaturas), a atividade despertou em alguns monitores o desejo de ser docente (principalmente, em institutos de idiomas) ou, pelo menos, de contribuir na formação de seus colegas e o mais importante: a vontade e a curiosidade para aprimorar os seus conhecimentos, inclusive, em uma futura pós-graduação.

Apesar de ainda estar em fase de desenvolvimento, a pesquisa crítica de colaboração revela que a partir das gravações e discussões, os monitores já puderem refletir acerca da sua prática e de como aperfeiçoar os atendimentos oferecidos. Nesse sentido, a pesquisa realizada contribui para uma formação crítica e reflexiva, o que deve ser um dos papeis primordiais do ensino superior. Independentemente do curso de graduação, é imprescindível pensar na formação de sujeitos que possam ser agentes transformadores atuantes, que possam fazer a diferença para si e para a sociedade em que estão inseridos.

É óbvio que a monitoria isoladamente pode não surtir todos os efeitos esperados, mas se trata de um passo fundamental para colaborar com o processo de ensinoaprendizagem e evitar que estudantes desistam de seus cursos por conta de dificuldades em uma ou mais disciplinas. E, esse ponto de vista, foi verificado nos primeiros encontros pelos monitores.

Espera-se que, ao longo da investigação, todos os participantes envolvidos possam refletir, debater criticamente e buscar uma transformação interna que seja benéfica, também, para os alunos que buscam pelos atendimentos, pois nem sempre monitores e docentes mais experientes observam e avaliam a sua prática. Uma instituição de ensino e/ou gestores e pesquisadores que incentivam, por meio de seus projetos e outras ações, uma cultura colaborativa e a avaliação da prática, propiciam ambientes ricos em possibilidades e com menor risco de fracasso no processo de ensino-aprendizagem. 


\section{REFERÊNCIAS}

AGUIAR, W. M. J. A Pesquisa Crítica de Colaboração na Formação e Trabalho Docente. In: 11 $^{\circ}$ Encontro de Pesquisa em Educação da Região Sudeste (ANPED Sudeste). Anais... São João Del Rey, MG: Universidade Federal de São João del Rey, 12-15 out. 2014.

CElAni, M. A. A. Prefácio. In: MAGAlÃES, M. C. C.; FIDAlgO, S. S. (orgs.). Questões de Método e de Linguagem na Formação Docente. Campinas, SP: Mercado das Letras, 2011.

DUARTE, J. Entrevista em Profundidade. In: DUARTE, J.; BARROS, A. (orgs.). Métodos e Técnicas de Pesquisa em Comunicação. $2^{a}$ ed. São Paulo: Atlas, 2008.

ENGESTRÖM, Y. The Future of Activity Theory: a rough draft. Cap. 19. In: SANNINO, A.; DANIELS, H.; GUTIERREZ, K.D. Learning and Expanding with Activity Theory. Cambridge, 2009.

Aprendizagem Expansiva: por uma reconceituação pela teoria

da atividade. Capítulo 4. In: ILLERIS, K. Teorias contemporâneas da Aprendizagem. São Paulo: Penso, 2013.

FREIRE, P. Pedagogia da Autonomia: saberes necessários à prática educativa. $38^{\mathrm{a}}$ ed. São Paulo: Paz e Terra, 2008.

GONZÁLEZ REY, F.; MARTINEZ, A. M. La personalidad: Su Educación y desarrollo. Habana: Pueblo y Educación, 1989.

LIBERALI, F. Cadeia Criativa: uma possibilidade para a formação crítica na perspectiva da teoria da atividade sócio-histórico-cultural. In: MAGALHÃES, M. C. C.; FIDALGO, S. S. (orgs.). Questões de Método e de Linguagem na Formação Docente. Campinas, SP: Mercado das Letras, 2011.

MACHADO, V. C. et al. A Pesquisa Crítica de Colaboração como Estratégia de Formação de Educadores com Vistas à Promoção da Alimentação Saudável do Escolar. In: XII Congresso Nacional de Educação (Educere). Anais... Curitiba: Pontifícia Universidade Católica do Paraná, 26-29 out. 2015, p. 32108-32120.

MAGAlHÃES, M. C. C. Pesquisa Crítica de Colaboração: Escolhas EpistemoMetodológicas na Organização e Condução de Pesquisas de Intervenção no Contexto Escolar. In: MAGALHÃES, M. C. C.; FIDALGO, S. S. (orgs.). Questões de Método e de Linguagem na Formação Docente. Campinas, SP: Mercado das Letras, 2011.

Escolhas Teórico-Metodológicas em Pesquisas com Formação de Professores: As Relações Colaborativo-Críticas na Constituição de Educadores. In: MATEUS, E.; OLIVEIRA, N. B. (org.). Estudos críticos da linguagem e formação de professores/as de línguas. Campinas, SP: Pontes, 2014. 
Projetos de Formação Contínua de Educadores para uma Prática Crítica. The Especialist, São Paulo, vol. 19, número 2, p. 169-184, 1998.

MELlO, H.; DUTRA, D. P. In: MAGAlhÃES, M. C. C.; FIDALGO, S. S. (orgs.). Questões de Método e de Linguagem na Formação Docente. Campinas, SP: Mercado das Letras, 2011.

NASCIMENTO, C. R.; SILVA, M. L. P.; SOUZA, P. X.. Possíveis Contribuições das Atividades de Monitoria na Formação dos Estudantes-Monitores do Curso de Pedagogia da Universidade Federal de Pernambuco - UFPE. Disponível em: https://www.ufpe.br/ce/images/Graduacao pedagogia/pdf/2010.1/possveis $\% 20$ contribui es $\% 20$ das $\% 20$ atividades $\% 20$ de $\% 20$ monitoria $\% 20$ na $\% 20$ forma.pdf. Acesso em 14 set. 2016.

NININ, M. O. G.. Pesquisa e Formação na Perspectiva Crítico-Colaborativa. In: MAGAlHÃES, M. C. C.; FIDALGO, S. S. (orgs.). Questões de Método e de Linguagem na Formação Docente. Campinas, SP: Mercado das Letras, 2011.

Critical collaborative research: focus on the meaning of collaboration and on mediational tools. Revista Brasileira de Linguística Aplicada (RBLA). Belo Horizonte. v.10, n.3, p. 773-797, 2010.

OLIVEIRA, W.; MAGALHÃES, M. C. C.. A Colaboração Crítica como uma Categoria de Análise da Atividade Docente. In: MAGALHÃES, M. C. C.; FIDALGO, S. S. (orgs.). Questões de Método e de Linguagem na Formação Docente. Campinas, SP: Mercado das Letras, 2011.

SCHAPPER, I. et al., Pesquisa Crítica de Colaboração: Intervenção no Cotidiano das Creches. In: Seminário de Grupos de Pesquisa sobre Crianças e Infâncias (GRUPECI), 4, 2014, Goiânia, Anais... Goiânia: Universidade Federal de Goiás, 2014. Disponível em: <http://www.fe.ufg.br/up/693/o/55a.pdf.grupeci> Acesso em: 25 jul. 2017 .

SMYTH, J. Teachers' work and the politics of reflection. American Educational Research Journal, vol. 29, n. 2, p. 267-300, 1992.

SOUZA, A. P.; ROSSO, A. J. Mediação e zona de desenvolvimento proximal (ZDP): entre pensamentos e práticas docentes. Educere. Curitiba. nov. 2011. Disponível em: < http://educere.bruc.com.br/CD2011/pdf/4604_3097.pdf> Acesso em: 14 mai. 2017.

TOPPING, K.; DURAN, D.; KEER, H. V. Using Peer Tutoring to Improve Reading Skills. Canadá: Routledge, 2015.

TORRES, P. L.; ALCANTARA, P. R.; IRALA, E. A. F. Grupos de Consenso: Uma Proposta de Aprendizagem Colaborativa para o Processo de Ensino-Aprendizagem. Revista Diálogo Nacional, v. 4, n. 13, set.-dez., 2004.

VYGOSTSKY, L. S. Pensamento e linguagem. São Paulo: Martins Fontes, 1989. 


\section{A AUTORA}

Gleice De Divitiis é licenciada em Letras (Inglês/Português), especialista em Psicopedagogia, mestre em Comunicação Social pela Universidade Metodista de São Paulo e doutoranda em Linguística Aplicada e Estudos da Linguagem pela Pontifícia Universidade de São Paulo. Atualmente, é professora em uma faculdade de tecnologia localizada no interior de São Paulo.

E-mail: gleicedivitiis@hotmail.com . 